\section{Case Reports in Gastroenterology}

Case Rep Gastroenterol 2020;14:458-466

DOI: 10.1159/000509501

Published online: October 8, 2020

(C) 2020 The Author(s)

Published by S. Karger AG, Basel www.karger.com/crg

This article is licensed under the Creative Commons Attribution-NonCommercial 4.0 International License (CC BY-NC) (http://www.karger.com/Services/OpenAccessLicense). Usage and distribution for commercial purposes requires written permission.

\title{
Atypical Manifestations of IgG4-Related Disease as Multiple Liver Abscesses with Subcapsular Tracts and Migratory Pulmonary Nodules Mimicking Parasitic Infection
}

\author{
Sawangpong Jandee ${ }^{a}$ Pattira Boonsrib \\ ${ }^{\mathrm{a} G a s t r o e n t e r o l o g y}$ and Hepatology Unit, Division of Internal Medicine, Faculty of \\ Medicine, Prince of Songkla University, Songkhla, Thailand; 'Diagnostic Radiology Unit, \\ Division of Radiology, Faculty of Medicine, Prince of Songkla University, \\ Songkhla, Thailand
}

\section{Keywords}

IgG4-related disease · Inflammatory pseudotumor - Liver abscesses · Migratory pulmonary nodule

\begin{abstract}
Immunoglobulin G4-related disease (IgG4-RD) is a fibroinflammatory condition that becomes more recognized as multi-systemic disorders, characterized by three histological hallmarks of IgG4-positive lymphoplasmacytic tissue infiltrate, storiform fibrosis, and obliterative phlebitis. This disease has been reported in virtually every organ system, but the hepatic manifestations remain poorly defined. Moreover, IgG4-RD can mimic many malignancies, inflammatory disorders and infectious diseases. This report revealed IgG4-related liver disease with atypical presentation presenting with multiple liver abscesses and linear tracts mimicking parasitic infection.

(C) 2020 The Author(s)

Published by S. Karger AG, Basel
\end{abstract}




\section{Case Reports in Gastroenterology}

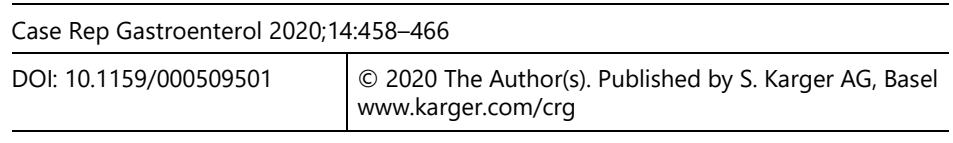

Jandee and Boonsri: IgG4 Liver Abscesses Mimicking Parasitic Infection

\section{Introduction}

Immunoglobulin G4-related disease (IgG4-RD) is increasingly being recognized as an emerging disease entity and mostly prevalent in older males; it has specific histopathological features with or without elevation of IgG4 levels [1]. Multiorgan involvement has been reported in more than $60 \%$ of patients with IgG4-RD. A wide range of organs may be affected, including the pancreas, kidneys, biliary tree, liver, salivary gland, orbit, aorta, and lungs [2]. The liver-related manifestations of IgG4-RD are heterogenous and less well described at present. They are classified into hepatic inflammatory pseudotumor (IPT) or chronic active hepatitis that is much less prevalent than biliary involvement in IgG4-related sclerosing cholangitis. The fundamental differential diagnoses of IgG4-IPT include lymphomas, hepatic abscesses, and other malignancies such as hepatocellular carcinoma and metastases. The diagnosis requires typical histopathological findings, elevated serum IgG4 and an abundance of IgG4 positive plasma cells in tissue.

\section{Case Presentation}

A 50-year-old farmer presented with a 1-month history of chronic non-productive cough, and epigastric and right upper quadrant pain. The pain was dull aching in characteristic. He also had anorexia, $3 \mathrm{~kg}$ of weight loss in 1 month (5.7\% from baseline) and fever at night. His symptoms were progressive during the month. On initial physical examination, he looked cachexic but had neither fever nor obvious dyspnea. Abdominal examination exhibited mild hepatomegaly (liver span $14 \mathrm{~cm}$ ) without tenderness. The rest of his physical examination was unremarkable.

\section{Investigations}

Laboratory testing revealed mild transaminitis with elevated alkaline phosphatase and very high total globulin level (Table 1). The complete blood count showed mild anemia, whereas differential white blood cells were all normal. An abdominal ultrasound revealed multiple ill-defined lobulated contour hypoechoic lesions at subcapsular region of both hepatic lobes containing internal cystic and necrotic portions. He was referred to our center due to high index of suspicion for malignant diagnosis. Abdominal CT scan (Fig. 1) showed multiple subcapsular liver abscesses with linear tracts. Subsequent upper abdominal MRI (Fig. 2) was performed and demonstrated rapidly increasing size of rim-enhancing lesions. New lesions were developed and visible as multiloculated and serpentine well-defined lesions, showing hypointense T1W and fluid signal in T2W, with septations scattering in both lobes. The largest one was up to $5.2 \mathrm{~cm}$ in size. They showed uniform rim enhancement and restricted DWI. Perilesional hemorrhage was also detected. Focal intrahepatic duct dilatation in segments 2 and 3, spleen $12.5 \mathrm{~cm}$ without focal lesion, a few aortocaval and paraaortic lymph nodes, about 1.0-1.4 cm, were detected. Chest CT scan (Fig. 3) illustrated migratory pulmonary nodules with surrounding ground glass opacity at right lower lung. Three consecutive collections of sputum AFBs were negative. 


\section{Case Reports in Gastroenterology}

\begin{tabular}{l|l}
\hline Case Rep Gastroenterol 2020;14:458-466 \\
\hline DOI: 10.1159/000509501 & $\begin{array}{l}\text { @ 2020 The Author(s). Published by S. Karger AG, Basel } \\
\text { www.karger.com/crg }\end{array}$ \\
\hline
\end{tabular}

Jandee and Boonsri: IgG4 Liver Abscesses Mimicking Parasitic Infection

\section{Differential Diagnosis and Investigations}

Initially, the differential diagnosis was focused on infection, especially parasitic infection or melioidosis. Two consecutive percutaneous ultrasound-guided liver biopsies were performed by radiological interventionist, but the pathological reports were inconclusive. Liver pathology demonstrated chronic abscess with massive plasmacytosis (kappa+, lambda+, IgG+, IgG4+ about 5-10\% of total IgG). Since the liver imaging was typical for parasitic liver abscesses, albendazole $800 \mathrm{mg} /$ day was also prescribed from the beginning, but his significant symptom and imaging did not improve.

As there was a strong suspicion of IgG4-related disease, adequate liver tissue pathology was necessary. Eventually, he underwent laparoscopic liver biopsy after an intense discussion. Intraoperative findings demonstrated adhesion at liver surface to abdominal wall without gross liver mass. Target biopsy was performed at hepatic segment 5 which revealed hard consistency. Liver pathology (Fig. 4) showed moderate portal inflammation with predominant plasma cell infiltrate in portal areas, liver parenchyma (IgG4-positive plasma cell $>50$ cells/HPF and IgG4/IgG $>40 \%$ ), and focal portal fibrosis. Fibrosis and chronic inflammation with congestion were found at capsular surface. Markedly elevated serum IgG4 level was reported $(5,330 \mathrm{mg} / \mathrm{dL})$. Finally, he was diagnosed with IgG4-related disease with atypical presentation; multiple liver abscesses with hemorrhagic tract and migratory pulmonary nodules.

\section{Treatment and Follow-Up}

Prednisolone $40 \mathrm{mg} /$ day orally was prescribed with a subsequent dose tapering. There was a rapid improvement of patient's symptoms and imaging. He gained weight and was well within a couple months. The follow-up CT scan after 3 months of prednisolone showed a decrease in the size of multiple rim-enhancing lesions. Some lesions were stable in size and some lesions were improving. No new lesion was noted. Liver function test was normal in all areas at 3 months (Table 1). Azathioprine $50 \mathrm{mg} /$ day was added on tapering prednisolone and was finally maintained at $5 \mathrm{mg} /$ day. Serum IgG4 level dramatically decreased from 5,330 to 186 $\mathrm{mg} / \mathrm{dL}$ at 6 months after treatment, but the follow-up liver imaging still illustrated stable small residual disease $(0.7-2.5 \mathrm{~cm})$ without new lesion and near resolving in pulmonary nodules. Until now, he has strictly adhered to immunosuppressive agents for 2.5 years with normal clinical and laboratory parameters, but the latest liver imaging still has stable residual disease without active findings (Fig. 5).

\section{Discussion}

Although multi-organ involvement in IgG4-RD has been widely reported, the hepatic manifestations remain poorly defined and are usually classified into two forms, hepatic IPT or chronic active hepatitis. Patients can present with a subtle lymphoplasmacytic IgG4 infiltration on liver biopsy only. The most common site of IPT is lungs, and only $8 \%$ of extrapulmonary IPTs were located in the liver [3]. Commonly, patients with IgG4-RD tend to present with mass-forming lesions and therefore are often suspected to have malignancy. This is contrary to our case report that presented with multiple liver abscesses. Extensive necrosis of IPTs might be responsible for this pathology. Moreover, the imaging also demonstrated 


\section{Case Reports in Gastroenterology}

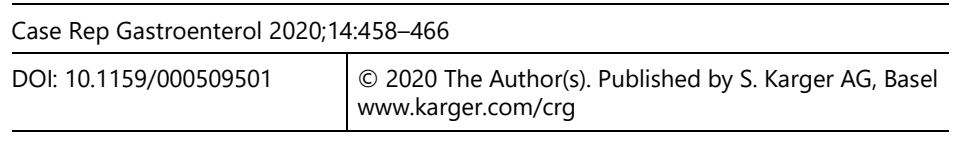

Jandee and Boonsri: IgG4 Liver Abscesses Mimicking Parasitic Infection

subcapsular tract with hemorrhage mimicking parasitic infection. Another organ in this case we have believed to be involved by IgG4 inflammatory process is migratory pulmonary nodule. Zen et al. [4] classified hepatic IPT into two major subtypes based on histological features, namely, lymphoplasmacytic and fibrohistiocytic types. The lymphoplasmacytic type was defined by an inflammatory process and corresponded to IgG4-RD demonstrating a dense IgG4positive plasma cell infiltrate, fibrosis, and obliterative phlebitis.

Imaging findings of hepatic IPT are non-specific and tend to present with tumefactive lesions and therefore are often suspected to have malignancy. They can manifest as a single or multifocal mass. On ultrasound images, they show hypoechoic or hyperechoic masses with increase through transmission and septation. Several patterns of enhancement are demonstrated on contrast-enhanced imaging. On MRI, these lesions are usually T1 hypointense and T2 hyperintense with heterogeneous enhancement [5]. Our case did not have typical imaging to diagnose IPT because of high signal intensity on diffusion-weighted images and perilesional edema resembling infectious liver abscess rather than tumor.

Histology from biopsy specimens is the gold standard in diagnosis of IgG4-related disease. A variety of cutoff points for the number of IgG4-postive plasma cells have been suggested, ranging from 10 to 50 IgG4-positive plasma cells per high-power field [6]. In practice, needle biopsy findings may not be sufficient for diagnosis and resection may be required. As in our case report, more invasive tissue assessment by laparoscopic liver biopsy was applied. Other laboratory abnormalities commonly seen are high serum IgG4 levels; levels $>182 \mathrm{mg} / \mathrm{dL}$ indicate significant IgG4-RD activity, but about $30 \%$ of histologically confirmed cases have normal levels of IgG4 [7]. Our case report had a large quantity of IgG4 level $(5,330 \mathrm{mg} / \mathrm{dL})$, which has never previously been mentioned in IgG4-RD cases.

Optimal treatment regimens, dosing and duration remain ill-defined according to retrospective studies. However, early aggressive treatment is suggested to prevent serious organ dysfunction and failure in late stage disease and in the case of extensive fibrosis. The mainstay of treatment is steroid therapy; a 2- to 4-week course of prednisolone 30-40 mg per day followed by dose tapering [8]. A response is usually seen within 4-6 weeks and is determined by improvement in clinical symptoms and organ function, reduction in size of the lesions in the affected organ by radiological imaging and decrease in serum IgG4 levels. Because of multiple lesions, very high IgG4 level indicated significant disease activity and due to the concern of disease flares and relapse, we added azathioprine to low-dose prednisolone for maintenance therapy.

Our case presented a diagnostic dilemma, as clinical presentation and imaging suggested an infectious etiology, and definite tissue pathology was not successful by fine needle biopsy. Moreover, divergent treatment strategies between infectious and immune-mediated inflammatory processes were influential in initiating immunosuppressive agents until definite diagnosis was confirmed.

IgG4-RD with hepatic involvement is rare and heterogeneous in manifestation. Early recognition and therapy are important to prevent serious and irreversible tissue damage. 


\section{Case Reports in Gastroenterology}

\section{Acknowledgement}

We are grateful to our patient for allowing us to publish his case and relevant images. We thank and appreciate the Division of Pathology, Songklanagarind Hospital, for the pathological images and suggestions.

\section{Statement of Ethics}

The patient in this case report has given his written informed consent to publish his case, and the manuscript was approved by the Office of Human Ethics Committee, Faculty of Medicine, Prince of Songkla University.

\section{Conflict of Interest Statement}

The authors have no conflicts of interest to declare.

\section{Funding Sources}

This research received no specific grant from any funding agency in the public, commercial, or not-for-profit sectors.

\section{Author Contributions}

S. Jandee made a substantial contribution to the case concept, drafting of the manuscript, and critical revision of the manuscript. P. Boonsri was responsible for radiological imaging, revision of the radiological description and manuscript.

\section{References}

1 Kamisawa T, Funata N, Hayashi Y, Eishi Y, Koike M, Tsuruta K, et al. A new clinicopathological entity of IgG4related autoimmune disease. J Gastroenterol. 2003;38(10):982-4.

2 Saeki T, Saito A, Hiura T, Yamazaki H, Emura I, Ueno M, et al. Lymphoplasmacytic infiltration of multiple organs with immunoreactivity for IgG4: IgG4-related systemic disease. Intern Med. 2006;45(3):163-7.

3 Coffin CM, Humphrey PA, Dehner LP. Extrapulmonary inflammatory myofibroblastic tumor: a clinical and pathological survey. Semin Diagn Pathol. 1998 May;15(2):85-101.

4 Zen Y, Fujii T, Sato Y, Masuda S, Nakanuma Y. Pathological classification of hepatic inflammatory pseudotumor with respect to IgG4-related disease. Mod Pathol. 2007 Aug;20(8):884-94.

5 Yan FH, Zhou KR, Jiang YP, Shi WB. Inflammatory pseudotumor of the liver: 13 cases of MRI findings. World J Gastroenterol. 2001 Jun;7(3):422-4.

6 Dhall D, Suriawinata AA, Tang LH, Shia J, Klimstra DS. Use of immunohistochemistry for IgG4 in the distinction of autoimmune pancreatitis from peritumoral pancreatitis. Hum Pathol. 2010 May;41(5):643-52.

7 Sah RP, Chari ST. Serologic issues in IgG4-related systemic disease and autoimmune pancreatitis. Curr Opin Rheumatol. 2011 Jan;23(1):108-13. 


\section{Case Reports in Gastroenterology}

8 Kamisawa T, Shimosegawa T, Okazaki K, Nishino T, Watanabe H, Kanno A, et al. Standard steroid treatment for autoimmune pancreatitis. Gut. 2009 Nov;58(11):1504-7.

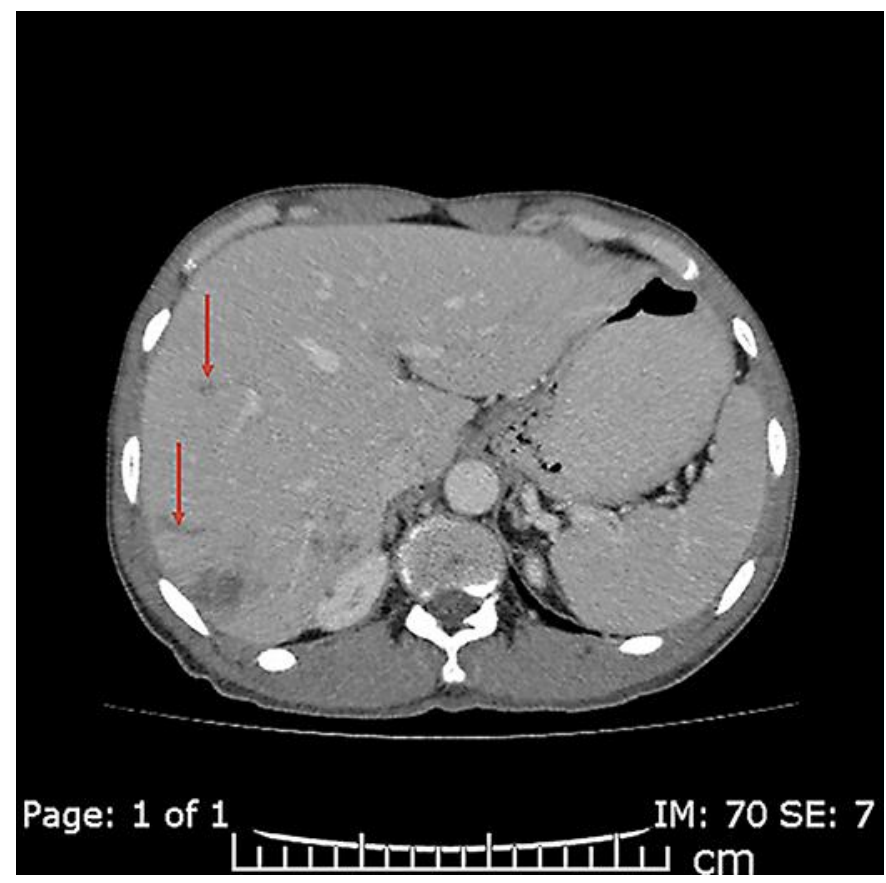

Fig. 1. Contrast-enhanced axial CT image at portal venous phase shows clustered small low-attenuating lesions at the subcapsular area of the right hepatic lobe. Note linear low-attenuating tracks (red arrows).
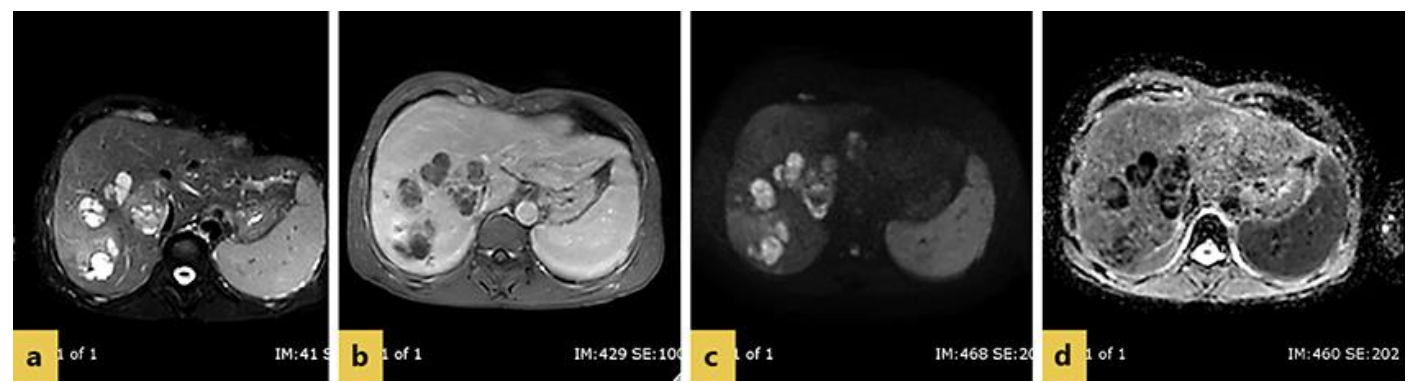

Fig. 2. a Axial T2-weighted MR image shows intermediate-signal-intensity perilesional edema surrounding hyperintense lesions. b Axial contrast-enhanced portovenous phase fat-suppressed T1-weighted MR image shows rim enhancement of the lesions, a finding consistent with hepatic abscesses. Diffusionweighted image (c) and apparent diffusion co-efficient image (d) show restriction of central core, a finding consistent with hepatic abscesses. 


\section{Case Reports in Gastroenterology}

\begin{tabular}{l|l}
\hline Case Rep Gastroenterol 2020;14:458-466 \\
\hline DOI: 10.1159/000509501 & $\begin{array}{l}\text { @ 2020 The Author(s). Published by S. Karger AG, Basel } \\
\text { www.karger.com/crg }\end{array}$ \\
\hline
\end{tabular}

Jandee and Boonsri: IgG4 Liver Abscesses Mimicking Parasitic Infection
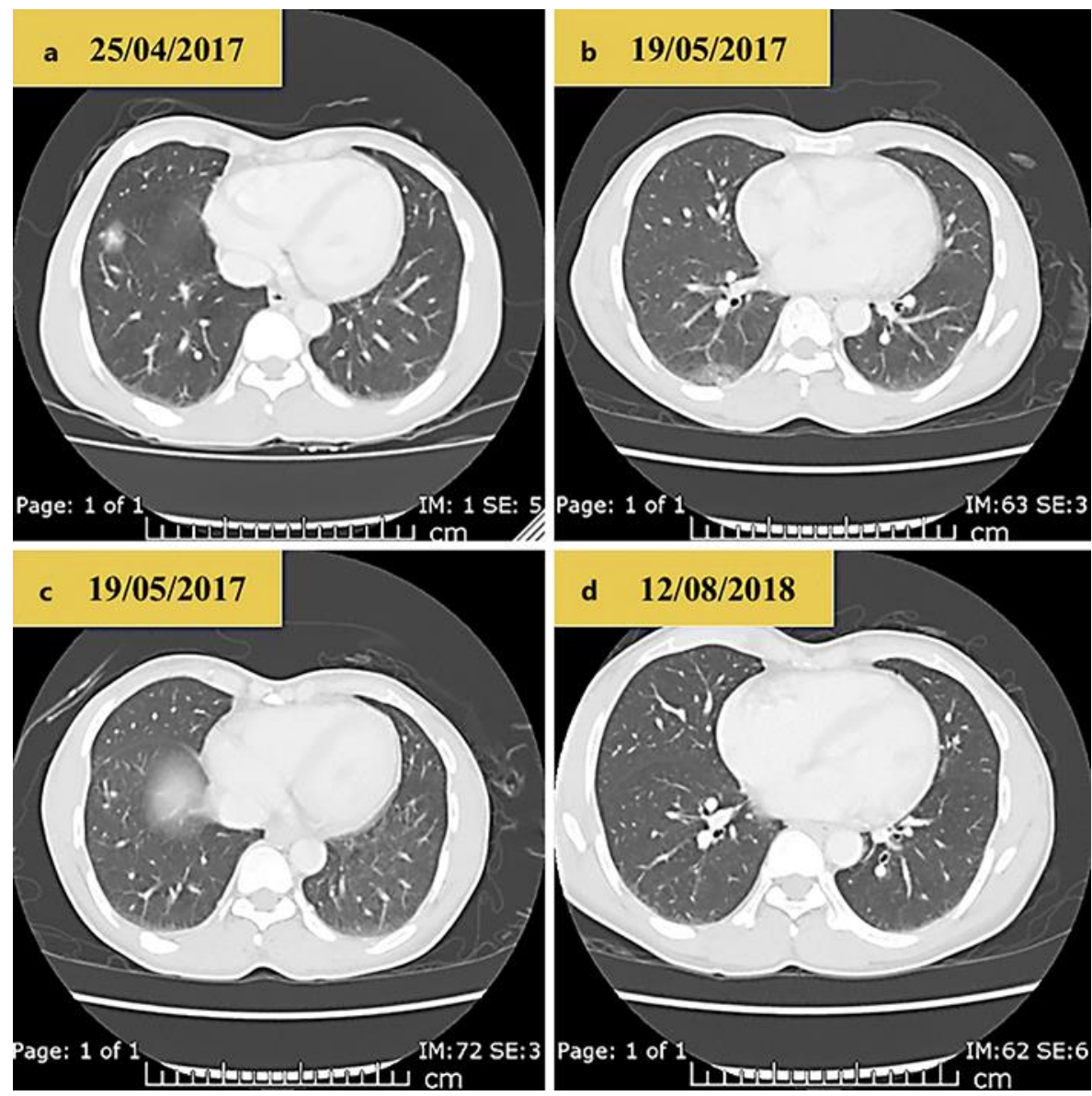

Fig. 3. A-64-year-old man with migratory pulmonary infiltrates. a The first CT chest (lung window) shows a subsolid nodule at the anterior basal segment of the right lower lobe. b, c One month later, repeated second CT of the chest shows a new subsolid nodule at the superior segment of the right lower lobe while the previously seen one at the anterior basal segment has disappeared. $\mathbf{d}$ Follow-up CT chest at 4 months after the first CT scan shows disappearance of the previously seen subsolid nodule at the superior segment of the right lower lobe. 


\section{Case Reports in Gastroenterology}

Case Rep Gastroenterol 2020;14:458-466
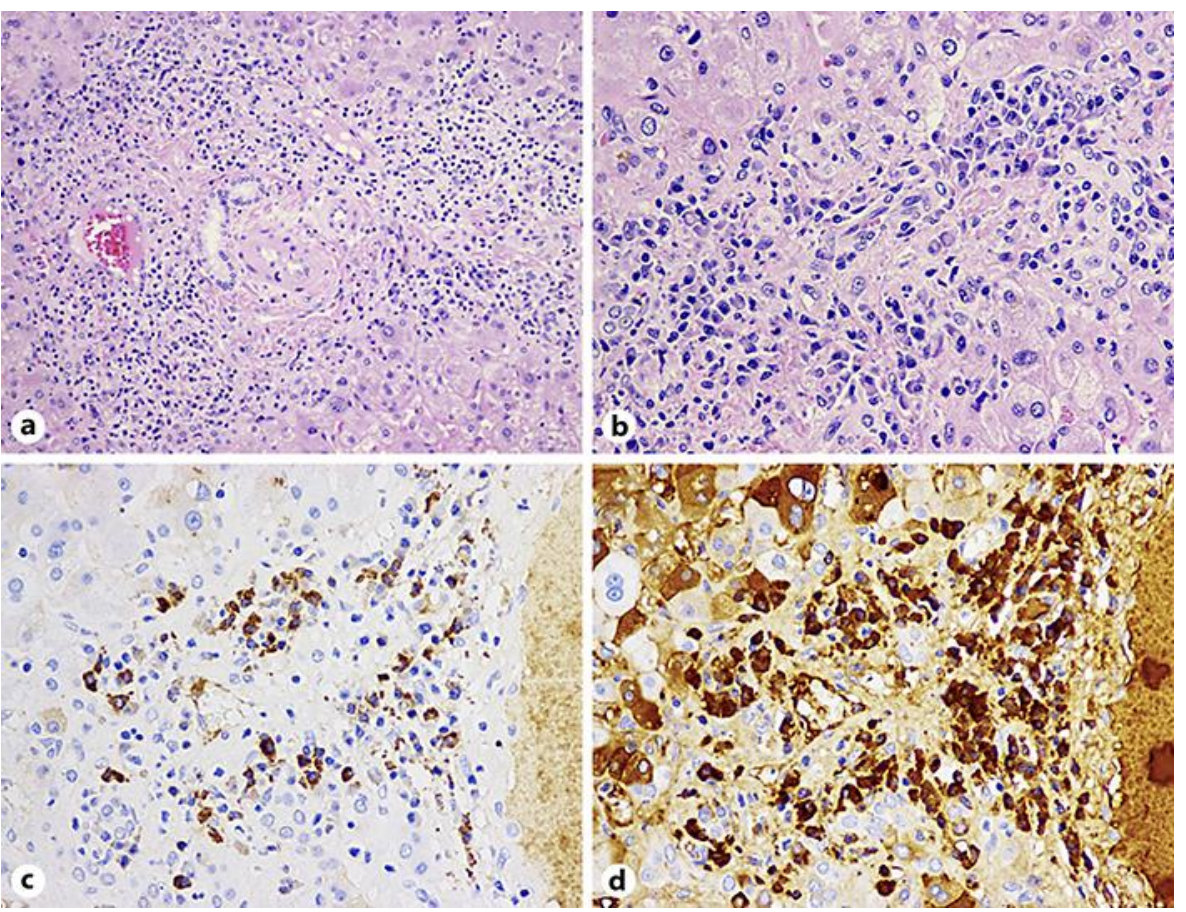

Fig. 4. a-d Histological features of IgG4-related liver disease. Liver tissue from laparoscopic liver biopsy demonstrating extensive plasm cell infiltration. a H\&E, $\times 100$. b H\&E, $\times 400$. Immunostaining demonstrating plasma cells expressing IgG4 $>50$ cells/HPF, and the ratio of IgG4/IgG-positive plasma cells is greater than $40 \%$. c IgG4 immunostaining. d IgG immunostaining.
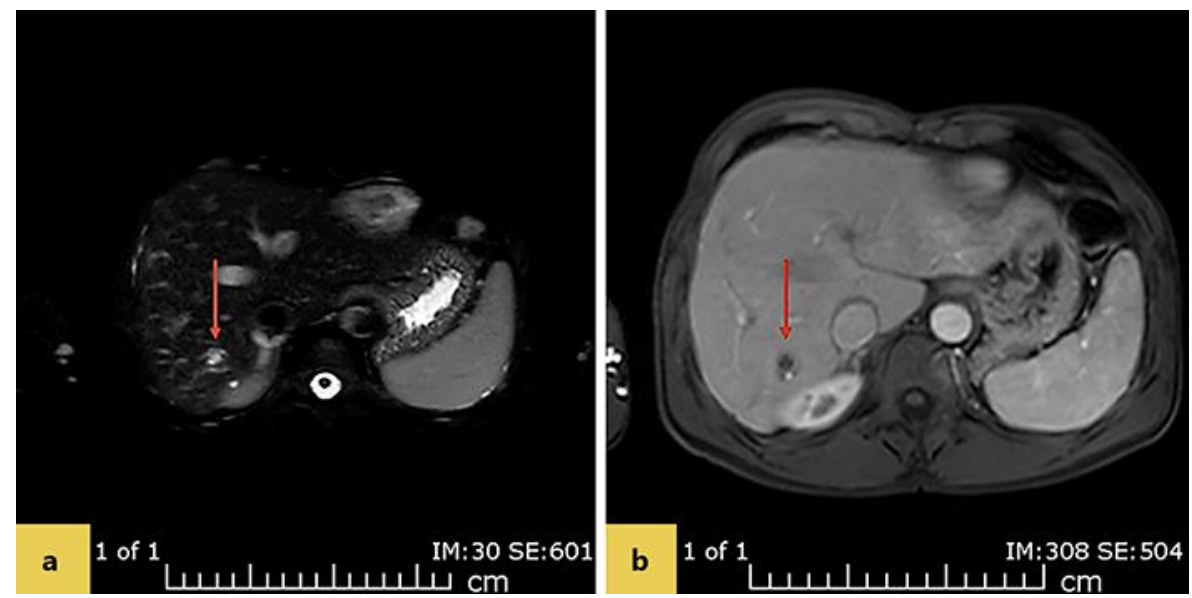

Fig. 5. a, b Follow-up MRI scans of the liver after prescribing immunosuppressants. Axial T2-weighted MR image (a) and axial contrast-enhanced portovenous phase fat-suppressed T1-weighted MR image (b) show a much smaller size of the hepatic lesion in the right hepatic lobe. 


\section{Case Reports in Gastroenterology}

\begin{tabular}{l|l}
\hline Case Rep Gastroenterol 2020;14:458-466 \\
\hline DOI: 10.1159/000509501 & $\begin{array}{l}\text { (c) 2020 The Author(s). Published by S. Karger AG, Basel } \\
\text { www.karger.com/crg }\end{array}$ \\
\hline
\end{tabular}

Jandee and Boonsri: IgG4 Liver Abscesses Mimicking Parasitic Infection

Table 1. Liver function test and serum IgG4 before and after prescribing immunosuppressive agents

\begin{tabular}{|c|c|c|c|c|c|c|c|}
\hline & $\begin{array}{l}\text { At initial } \\
\text { exam }\end{array}$ & $\begin{array}{l}\text { Before starting } \\
\text { steroid }\end{array}$ & $\begin{array}{l}1 \text { month after } \\
\text { steroid }\end{array}$ & $\begin{array}{l}3 \text { months after } \\
\text { steroid }\end{array}$ & $\begin{array}{l}6 \text { months after } \\
\text { steroid }\end{array}$ & $\begin{array}{l}1 \text { year after AZA } \\
\text { maintenance }\end{array}$ & $\begin{array}{l}2 \text { years after AZA } \\
\text { maintenance }\end{array}$ \\
\hline $\mathrm{TB}, \mathrm{mg} / \mathrm{dL}$ & 1.27 & 0.50 & 0.43 & 0.39 & 0.43 & 0.24 & 0.17 \\
\hline $\mathrm{DB}, \mathrm{mg} / \mathrm{dL}$ & 0.96 & 0.32 & 0.21 & 0.20 & 0.20 & 0.11 & 0.40 \\
\hline AST, U/L & 54 & 32 & 32 & 21 & 25 & 21 & 18 \\
\hline ALT, U/L & 82 & 31 & 30 & 34 & 24 & 16 & 16 \\
\hline ALP, U/L & 493 & 319 & 147 & 84 & 77 & 73 & 75 \\
\hline $\mathrm{TP}, \mathrm{g} / \mathrm{dL}$ & 10.2 & 13.3 & 9.6 & 7.1 & 7.2 & 6.9 & 7.3 \\
\hline Albumin, g/dL & 2.7 & 2.9 & 4.0 & 4.5 & 4.4 & 4.3 & 4.9 \\
\hline Globulin, g/dL & 7.5 & 10.4 & 5.6 & 2.6 & 2.8 & 2.6 & 2.4 \\
\hline IgG4, mg/dL & & 5,330 & & & 186 & & \\
\hline \multirow[t]{2}{*}{ Treatment } & & prednisolone & & add AZA & & & \\
\hline & & $40 \mathrm{mg} /$ day & & $50 \mathrm{mg} /$ day & & & \\
\hline
\end{tabular}

LFT, liver function test; AZA, azathioprine; TB, total bilirubin; DB, direct bilirubin; AST, aspartate transaminase; ALT, alanine transaminase; ALP, alkaline phosphatase. 